\title{
Probing Solid Transformation of Akaganéite to Iron Oxides by in situ Transmission Electron Microscopy
}

X. ZHANG ${ }^{1}$, Y. HE ${ }^{1}$, L. KOVARIK ${ }^{1}$, M.E. BOWDEN ${ }^{1}$, M.H. ENGELHARD ${ }^{1}$, Y. DU ${ }^{1}$, L. LIU ${ }^{1}$, C. WANG ${ }^{1}$, J.J. DE

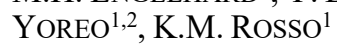

${ }^{1}$ Pacific Northwest National Laboratory, Richland, WA

${ }^{2}$ University of Washington, Seattle, WA

Mineral phase transformation where primary particles are replaced by more stable phases is a common phenomenon in nature. Transformations of iron-based minerals are important for predicting impacts of iron cycling, and also for designing novel materials. To probe atomic-scale pathways and to quantify the kinetic parameters controlling rates, we investigated thermal transformation of akaganéite $(\beta-\mathrm{FeOOH})$ to anyhydrous iron oxide polymorphs in vacuo via in situ transmission electron microscopy (TEM). We observed the crystal structure of $\beta-\mathrm{FeOOH}$ first undergoes disordering upon heating to $200^{\circ} \mathrm{C}$, and then the morphology evolved from solid nanowires to highly nanoporous nanowires composed of maghemite, the grain size of which is inversely related to density of the pores. Furthermore, we found that phase outcomes strongly depend on the initial size of the $\beta-\mathrm{FeOOH}$ nanowires. For diameters smaller than $20 \mathrm{~nm}$, the final product is maghemite; transformation of maghemite to hematite was not observed even upon heating to $500^{\circ} \mathrm{C}$ for $12 \mathrm{~h}$, which only eliminated the nanoporosity. For initial $\beta-\mathrm{FeOOH}$ nanowires with diameters larger than $20 \mathrm{~nm}$ the final product is more variable depending on the heating temperature, time, and pressure. The findings provide detailed new insights into processes controlling thermal phase transformation mechanisms among iron oxides at dry conditions, and may also help in the design new maghemite and hematite nanomaterials. 